\title{
What Is Narcissistic Personality Disorder? Lay Theories of Narcissism
}

\author{
Kirstie Wright ${ }^{1}$, Adrian Furnham ${ }^{1,2}$ \\ ${ }^{1}$ Research Department of Clinical, Educational and Health Psychology, University College London, London, UK \\ ${ }^{2}$ Norwegian Business School (BI), Olso, Norway \\ Email: a.furnham@ucl.ac.uk
}

Received 16 May 2014; revised 12 June 2014; accepted 5 July 2014

Copyright (C) 2014 by authors and Scientific Research Publishing Inc.

This work is licensed under the Creative Commons Attribution International License (CC BY). http://creativecommons.org/licenses/by/4.0/

(c) (i) Open Access

\section{Abstract}

There are various studies on mental health literacy which examine lay people's knowledge and understanding of various mental disorders. Many are interested in beliefs about cause, manifestation and cure as well as the relationship between those beliefs. This study examines lay beliefs regarding the manifestations, aetiology and treatment of Narcissistic Personality Disorder (NPD), and their determinants using a questionnaire divided into three parts. Participants $(\mathbf{N}=201)$ answered 45 attitudinal statements designed for this study regarding NPD. They consisted of 18 manifestation items, 15 aetiology items and 12 treatment items referring to NPD. They also completed the Narcissistic Personality Inventory. Each section of the questionnaire was factor analysed to determine the structure of those beliefs. Factors derived from a principle component analysis of lay beliefs demonstrate poor knowledge of NPD. Factors derived from the manifestations, aetiology and treatment section were modestly and coherently correlated. No demographic factors correlated with all aspects of mental health literacy and lay theories. People are surprisingly misinformed about NPD. They believed that narcissists manifested superficiality and social problems, business abilities and fragility. No distinction was made between biological and psychological causes or genetics and early negative events. Inability to identify NPD may account for many reports of sub-clinical narcissism being associated with leadership derailment.

\section{Keywords}

Narcissism, Mental Health Literacy, Aetiology, Treatment

\section{Introduction}

The present study concerns lay people's beliefs about narcissism. It is surprising that despite the prevalence of 
personality disorders and a rise of narcissism in Western culture (Lasch, 1978) that little research has been carried out into lay theories of NPD. This may be due, in part, to difficulties defining NPD. NPD is found in cluster B of the personality disorders in the Diagnostic and Statistical Manual of Mental Disorders (DSM-IV-R, there have been few empirical studies investigating whether the DSM criteria are useful in defining NPD as the DSM criteria are based on clinical anecdotes rather than empirical studies (Cooper \& Ronningstam, 1992). Pincus and Lukowitsky (2010) concluded that relying on DSM-IV criteria may impede the recognition of clinical narcissists.

Lay theories of NPD are of particular interest due to difficulties in defining NPD causing NPD to be controversial and likely to be deleted from DSM-V (Campbell \& Miller, 2011). Such doubts are supported by Cain, Pincus and Ansell (2008) who found that the DSM-IV criteria for NPD have low discriminate validity and that a clinical diagnosis of NPD is only moderately stable over time. However, Ronningstam (2011) suggests that NPD should be included into DSM-V but that the criteria should focus on behaviours that are less affected by context changes such as self-esteem regulation. A suggested prevalence rate of 6\% (Stinson, Dawson, Goldstein, Chou, Huang, Smith et al., 2008) in the general population suggests that NPD affects many people especially due to the distress that narcissist's cause to those around them (Twenge \& Campbell, 2009) and therefore should be kept in DSM-V and NPD is currently included in the draft DSM-V.

\subsection{Behavioural Manifestations}

The classic literature has focused on narcissist's inability to regulate self-esteem and a satisfying self representation of themselves causing them to demand attention and admiration to feed their self-esteem (Cooper \& Ronningstam, 1992). A key feature of NPD is a lack of empathy (Ritter, Dziobek, Preisler, Ruter, Vater, Fydrich et al., 2011). This causes narcissists to use others for their own gain and makes close long-term relationships only successful when the narcissist is getting the self-esteem boost that they need from the relationship (De Wall, Buffardi, Bonser, \& Campbell, 2011). Grandiosity (exaggerating talents and an unrealistic sense of superiority) has been found to be key in discriminating NPD from other personality disorders (Ronningstam \& Gunderson 1991). When a narcissists self-esteem is not gratified by others or they are criticised this can cause them to turn to anger (Ronningstam \& Gunderson, 1991). Gratification from achievements comes from external praise rather than an inner sense of an achievement being accomplished (Cooper \& Ronningstam, 1992). These traits vary according to the severity of the narcissism and not every trait will be seen in all cases (Kernberg, 2010).

However, there is disagreement surrounding whether the classical portrayal of NPD is valid. For example narcissists with low self esteem who are threatened show less anger than narcissists with high self-esteem (Thomaes \& Bushman, 2011). This disputes the narcissist portrayed in the classical literature that has low self esteem and turns to anger when criticised. This has resulted in the suggestion that the classical account of NPD has two dimensions: Grandiose and Vulnerable Narcissism (Wink, 1991; Dickinson \& Pincus, 2003). It has even been suggested that the manifestation of grandiosity of which there is much agreement on could be improved by recognising two different dimensions of NPD and specifying the patterns of grandiosity related to each dimension (Ronningstam \& Gunderson, 1990). Miller, Hoffman, Gaughan, Gentile, Maples and Campbell (2011) argue that the primary feature shared by both dimensions of narcissism is a tendency to act antagonistically towards others and that they differ on many other features. Vulnerable narcissists have grandiose fantasies but are timid, insecure and consequently do not appear narcissistic on the surface. Grandiose narcissists have higher levels of happiness and life satisfaction (Rose, 2001) and are more exhibitionistic than vulnerable narcissists (Wink, 1991).

The two dimensions of narcissism have been intertwined in many pieces of research with the distinction not consistently made (Miller et al., 2011). This has had "serious consequences for the field as a great deal of unreliability are introduced into our communications, assessments and conceptualizations” of NPD (Miller, Widiger, \& Campbell, 2010: p. 641). This is particularly true given the finding that nomological networks of the two dimensions of NPD are unrelated (Miller et al., 2011). Pincus and Lukowitsky (2010) suggest that the poor validity of the DSM-IV criteria is due to overemphasising grandiose traits over the vulnerable traits of NPD.

\subsection{Aetiology}

Theories on what causes NPD tends to focus on environmental factors over biological factors. The two main environmental theories are those of Kernberg (1975) and Kohut (1977) who focus on the parent-child relationship. Genetics may also play a role in causing NPD because narcissism is highly heritable, although there is a lack of 
research demonstrating exactly how genetics causes NPD (Paris, 1996). This is supported by newborns showing differences in temperament (self regulation and reactivity) which is thought to have a biological basis (Rothbart, 1991). Two views have been put forward on how temperament differences can cause personality disorders. One is that the infant's temperament can cause problems for the caregivers which can cause the infants problems to worsen (Rutter \& Quinton, 1984). The second is that certain temperaments may put children at risk of certain environmental stressors (Paris, 1996). This demonstrates that an interaction between genes (temperament) and the environment (early parenting) is likely to cause NPD and is further supported by Dunn and Plomin (1990) who found that personality traits are up to $50 \%$ genetically determined.

The cause of NPD may be different depending on the different dimensions of narcissism because vulnerable narcissism is strongly related to an anxious model of attachment (Dickinson \& Pincus, 2003) whereas grandiose narcissism is related to a secure or dismissive attachment style (Dickinson \& Pincus, 2003). Vulnerable narcissism has been found to be significantly related to child abuse unlike grandiose narcissism (Otway \& Vignoles, 2006). More research is needed into how the different theories of what causes NPD relate to vulnerable and grandiose narcissism and may lead to a more adequate explanation of the cause of NPD. Therefore due to the different theories of the cause of NPD (although there is a general consensus in psychoanalytical literature that early parenting plays a role (Otway \& Vignoles, 2006)) it is interesting to investigate lay theories on this issue. The findings could be useful to determine what information is most needed in health campaigns regarding NPD.

\subsection{Treatment}

Treatments of NPD have traditionally come from a psychodynamic and psychoanalytic framework (Adler, 1986). Long term psychodynamic therapies are thought to be the best form of treatment (Turner, 1994). An example of a well used and tested psychodynamic treatment for NPD is that of Kohut's (1971). The aim of the treatment is for the patient to idolize the therapist because they did not get to idolize their parents as a child. Patients also get to see how their child-parent relationship could have led to their NPD.

Behavioural treatments of NPD focus on the contexts in which the narcissistic behaviours occur and the behaviours that cause the individual and those around them harm. Behavioural treatments have started to appear more in the literature (Koerner, Kohlenberg, \& Parker, 1996). Cognitive therapies focus on developmental issues and on building a therapist-client relationship to modify the narcissist's beliefs using certain strategies (Oldham \& Morris, 1995). Treatment varies with the severity and symptoms present (Kernberg, 2010). Family and couples therapy is also effective in treating NPD (Harman \& Waldo, 2004). Pharmaceuticals are not normally used for NPD itself but for illnesses that may co-occur with NPD such as depression (Oldham \& Morris, 1995). Due to the range of treatments available for NPD, it is interesting to investigate lay beliefs.

Furnham, Kirby and McClelland (2011) found NPD was the least likely to be seen as in need of treatment and was attributed to psychological rather than biological causes. Their study contained general aetiology and treatment questions that applied to all personality disorders and therefore there is a need for research with questions specific to NPD.

\subsection{This Study}

This study aims to investigate laypeople's beliefs regarding the manifestations, aetiology and treatment of NPD using three exploratory principle component analyses on attitudinal statements specific to NPD to determine whether laypeople's beliefs can be reduced into interpretable factors. This study also aims to investigate whether laypeople have a monological belief system regarding NPD. No specific predictions were made because this research is largely exploratory.

This study aimed to investigate whether participants own narcissistic traits measured by the NPI-16 (Ames, Rose, \& Anderson, 2006), a shortened version of the original NPI related to laypeople's theories regarding the aetiology, manifestations and treatment of NPD, participants identification and likeliness to suggest help for all vignettes. This was to investigate whether people's narcissistic traits affect their lay theories and mental health literacy. It was hypothesised that NPI score would relate to participants lay beliefs, identification and likeliness to suggest help for all NPD vignettes.

This study therefore aimed to investigate the demographics that influence mental health literacy and lay theories regarding NPD. It was hypothesised that the study of mental illness (Furnham, Daoud, \& Swami, 2009), personal experience of mental illness (Furnham, Abajian, \& McClelland, 2011), qualifications (Lauber, Carlos, 
\& Wolf, 2005), age (Fisher \& Goldney, 2003) and gender (Wang, Adair, Fick, Lai, Waye, Jorm, \& Addington, 2007) would correlate with the correct identification of vignettes, participants likeliness to suggest help and lay beliefs regarding the manifestations, aetiology and treatment of NPD.

\section{Method}

\subsection{Participants}

Two hundred and one participants were recruited opportunistically in public places $(\mathrm{N}=130(65 \%))$, with the assistance of another researcher $(\mathrm{N}=24)$ and online $(\mathrm{N}=71(35 \%))$ via email through contacts of the author. Participation was voluntary and no incentives were given for participating. Of those who answered the relevant demographic questions there were 115 (58\%) females and 84 (42\%) males. There was an age range of 18 to 85 years $(\mathrm{M}=32.8$, standard deviation $(\mathrm{SD})=17.1)$. The majority of participants were of white ethnicity $(75.9 \%, \mathrm{~N}$ $=151)$, with Asian (7.5\%, $\mathrm{N}=15)$, Chinese (6.5\%, $\mathrm{N}=13)$, Black $(5 \%, \mathrm{~N}=10)$, Mixed $(4.5 \%, \mathrm{~N}=9)$ and other ethnicities (1\%) also represented. In relation to qualifications 30.5\% $(\mathrm{N}=61)$ had A levels, $19 \%(\mathrm{~N}=38)$ had undergraduate degrees, $16.5 \%$, $(\mathrm{N}=33)$ had GCSEs, $15 \%(\mathrm{~N}=30)$ were still in full time education, $6 \%(\mathrm{~N}=12)$ had other higher qualifications, $5 \%(\mathrm{~N}=10)$ had no qualifications, $4 \%(\mathrm{~N}=8)$ had completed a foundation course and $4 \%(\mathrm{~N}=8)$ had a postgraduate degree. There was a NPI score range of 1 to $7(\mathrm{M}=4.86, \mathrm{SD}=.96)$. Lastly $19.7 \%$ had studied a mental illness $(\mathrm{N}=39)$ and $6.1 \%$ had been diagnosed with a mental illness $(\mathrm{N}=12)$.

\subsection{Apparatus and Materials}

Lay Theories: Forty-five attitudinal statements were presented to participants. They consisted of 18 manifestation items, 15 aetiology items and 12 treatment items referring to NPD. These items were derived from the literature (Cooper \& Ronningstam, 1992; Kernberg, 2010) as well as from Furnham, Daoud and Swami (2009). They were piloted for comprehensability. Participants were asked to rate on a likert scale (from 7 Strongly Agree to 1 Strongly Disagree) their agreement with each statement.

NPI: Participants completed the NPI-16 (Ames, Rose, \& Anderson, 2006) which is a measure of narcissistic traits. It consists of 16 items which are pairs of statements; one is the narcissistic choice and the other is the nonnarcissistic choice, with participants marking their agreement with the pairs of statements on a likert scale (7 Strongly Agree to 1 Strongly Disagree Statement B). It has been found to have internal, discriminate and predictive validity (Ames, Rose, \& Anderson, 2006).

\subsection{Procedure}

Participants were invited to fill out the questionnaire either online or in person by the experimenter. Half of participants ( $N=101,(50 \%)$ ) filled out the questionnaire which started with a male depression vignette and the other half $(\mathrm{N}=100,(50 \%))$ filled out the questionnaire which started with a female depression vignette. The questionnaire took approximately 20 - 25 minutes to complete. All participants gave informed consent and it was explained that their responses were anonymous, confidential and that they had the right to withdraw.

\section{Results}

\subsection{Manifestations}

A PCA with varimax rotation was carried out on the 18 behavioural manifestation items. Item 15 was reversed. Upon an initial inspection of the communalities it was discovered that two of the 18 items, Item 9 (The onset of narcissism can occur anytime from early childhood) and Item 17 (Narcissism is not a disorder merely a strong personality) had low communalities (.47 and .48 respectively) and were therefore excluded from the PCA. The communality cut off point was .50. A PCA was then run with the remaining 16 items. The Bartlett's test of sphericity was significant at $\chi^{2}=971.90, \mathrm{df}=120, p<.001$ which together with the size of the Kaiser-Meyer-Olkin measure of sampling adequacy KMO $=.84$ demonstrated that the remaining 16 manifestation items had sufficient common variance for a PCA (Tabachnick \& Fidell, 2001). Inspection of the Scree plot (Cattell, 1966) and factor loadings (Comrey \& Lee, 1992) were used to identify appropriate components. The PCA revealed three factors that accounted for $58 \%$ of the variance.

The first factor contained seven items referring to Superficiality and Social Problems (Eigen value $=3.85$, 
accounting for $24 \%$ of the variance). The second factor contained three items referring to Business Abilities (Eigen value $=2.04$, accounting for $13 \%$ of the variance). The third factor contained three items referring to Fragility (Eigen value $=1.75$, accounting for $11 \%$ of the variance). The factor loadings for each item in each factor are reported in Table 2, along with factor scores calculated by taking the mean response associated with a factor. A high mean indicates strong agreement with a factor and a low mean indicates low agreement. Participants rated that NPD manifests itself in Superficiality and Social Problems more than Fragility and Business Abilities. Cronbachs $\alpha$ coefficients were of low to moderate reliability and are also reported in Table 1 (Kline, 1986).

\subsection{Aeitiology}

A PCA was carried out using the same criteria as the above PCA with the 15 aetiology items. Item 38 was reversed. The communalities of three items, Item 20 (Delusional beliefs can cause narcissism), Item 24 (People can be predisposed to develop narcissism by having an oversensitive temperament at birth) and Item 27 (Narcissism is a defence mechanism and therefore caused by repressed emotions) were low (.44, .34 and .41 respectively) and excluded from further analysis. A PCA on the remaining 12 items was carried out and demonstrated the existence of three factors accounting for $56 \%$ of the variance. The Bartlett's test of sphericity was significant at $\chi^{2}=672.50, \mathrm{df}=66, p<.001$ which together with size of the Kaiser-Meyer-Olkin measure of sampling adequacy $\mathrm{KMO}=.77$ demonstrated that the 12 remaining aetiology items had sufficient common variance for a PCA (Tabachnick \& Fidell, 2001). The first factor contained six items referring to Social and Cogni-

Table 1. The means, standard deviations, factor loadings, Eigen values and alphas of the 16 manifestation items.

\begin{tabular}{|c|c|c|c|c|}
\hline Factor and Items & Eigen Value & Variance/Factor Loading & Mean (SD) & Alpha \\
\hline 1) Superficiality and Social Problems & 3.85 & 24 & $4.44(.98)$ & .60 \\
\hline Narcissists strive for attention. & & .79 & & \\
\hline Individual's narcissistic traits can vary across a person's lifetime. & & .76 & & \\
\hline Narcissists can handle criticism well. & & .75 & & \\
\hline Narcissism is Rife in today’s society. & & .69 & & \\
\hline $\begin{array}{l}\text { Having a narcissistic personality can cause problems in many } \\
\text { areas of life such as work, relationships and financial matters. }\end{array}$ & & .69 & & \\
\hline Narcissists are vain. & & .68 & & \\
\hline Narcissists are low in Emotional Intelligence. & & 61 & & \\
\hline 2) Business Abilities & 2.04 & 12.7 & $4.02(1.12)$ & .65 \\
\hline Narcissists are visionaries. & & .79 & & \\
\hline Narcissists are likely to have a high IQ. & & .77 & & \\
\hline Narcissists make good leaders. & & .71 & & \\
\hline 3) Fragility & 1.75 & 10.5 & $4.15(1.07)$ & .49 \\
\hline Narcissists have a fragile self esteem. & & .74 & & \\
\hline Narcissists are likely to suffer from other mental disorders. & & .63 & & \\
\hline Narcissist often set unrealistic goals. & & .56 & & \\
\hline
\end{tabular}

\section{Non Loading Items}

Narcissists are more likely to be men than women.

Narcissists cannot have close healthy relationships.

Narcissists are manipulative. 
tive Explanations (Eigen value $=3.15$, accounting for $26 \%$ of the variance). The second factor contained two items referring to Genetics and Early Negative Events (Eigen value $=1.83$, accounting for $15 \%$ of the variance). The third factor contained two items referring to Negative Feelings (Eigen value $=1.74$, accounting for $15 \%$ of the variance). The factor loadings for each item in each factor are reported in Table 2, along with factor scores. Participants rated that the cause of NPD can be explained by Social and Cognitive Explanations more than Negative Feelings and Genetic and Early Negative Events. Cronbachs $\alpha$ coefficients were of low to high reliability (Kline, 1986) and are also reported in Table 2.

\subsection{Treatment}

PCA was carried out with the same criteria as the above two PCAs with 9 of the 12 treatment items. Three of the items, Item 34 (Narcissism can be successfully treated by Freudian psychoanalysis), Item 36 (Group therapy can effectively treat narcissism) and Item 39 (Although some narcissists behaviour can be treated a person's personality cannot be dramatically changed) were excluded due to low communalities (.37, .47 and .31 respectively). The PCA carried out on the 9 items demonstrated the existence of two factors accounting for $56 \%$ of the variance. The Bartlett's test of sphericity was significant $\chi^{2}=525.25, \mathrm{df}=36, p<.001$ which together with the Kaiser-Meyer-Olkin measure of sampling adequacy KMO $=.78$ demonstrated that the remaining nine items had sufficient common variance for a PCA (Tabachnick \& Fidell, 2001). The first factor consisted of six items referring to Treatability and Less Severe Treatment (Eigen value 3.14, accounting for 35\% of the variance).

The second factor consisted of three items referring to Clinical Treatment (Eigen value 1.93, accounting for $22 \%$ of the variance). The factor loadings for each item in each factor are reported in Table 3, along with factor scores. Participants rated Treatability and Less Severe Treatment as more effective than Clinical Treatment. Cronbachs $\alpha$ coefficients were of low to moderate reliability and are also reported in Table 3 (Kline, 1986).

Table 2. The means, standard deviations, factor loadings, Eigen values and alphas of the 12 aetiology items.

\begin{tabular}{|c|c|c|c|c|}
\hline Factor and Items & Eigen Value & Variance/Factor Loading & Mean (SD) & Alpha \\
\hline 1) Social and Cognitive Explanations & 3.15 & 26.2 & $4.18(1.06)$ & .81 \\
\hline
\end{tabular}

Narcissism can be caused by learning narcissistic

behaviours from parents.

Narcissism can be caused by distorted cognitions.

Narcissism can be caused by disruptions to the attachment process with the primary caregiver.

Narcissism can be caused by a lack of opportunity to gain approval from parents.

.60

Narcissism is caused by society's approval of boasting about our accomplishments and status.

2) Genetics and Early Negative Events

Narcissism is hereditary and therefore genetic.

Narcissism is caused by physical/mental abuse as a child/adolescent.

3) Negative Feelings

Low self esteem causes narcissistic traits.

\section{Non Loading Items}

Narcissism is caused by purely environmental/social factors. 
Table 3. The means, standard deviations, factor loadings, Eigen values and alphas of the 9 treatment items.

\begin{tabular}{|c|c|c|c|c|}
\hline Factor and Items & Eigen Value & Variance/Factor Loading & Mean (SD) & Alpha \\
\hline Treatability and Less Severe Treatment & 3.14 & 34.89 & $4.22(.73)$ & .57 \\
\hline Family therapy can be effective in treating narcissism. & & .78 & & \\
\hline $\begin{array}{l}\text { Narcissism can be improved by environments } \\
\text { in which cooperation is necessary. }\end{array}$ & & .75 & & \\
\hline Counselling can improve narcissistic behaviour. & & .74 & & \\
\hline $\begin{array}{l}\text { Narcissism can be successfully treated by } \\
\text { cognitive behavioural therapy. }\end{array}$ & & .70 & & \\
\hline Narcissism cannot be treated. & & .70 & & \\
\hline $\begin{array}{l}\text { Narcissists can improve their behaviour without treatment } \\
\text { but by realising the problems that their behaviour causes. }\end{array}$ & & .64 & & \\
\hline Clinical Treatment & 1.93 & 21.49 & $3.79(1.18)$ & .63 \\
\hline Narcissism can be effectively treated by medication. & & .83 & & \\
\hline $\begin{array}{l}\text { It is necessary to see a clinical psychologist } \\
\text { in order to recover from narcissism. }\end{array}$ & & .73 & & \\
\hline Inpatient hospital care can aid the treatment of narcissists. & & .64 & & \\
\hline
\end{tabular}

\subsection{Correlations}

Bivariate Pearson correlations were conducted between each of the eight extracted factors, the study of mental illness, personal diagnosis of a mental illness, qualifications, gender age and NPI score to investigate whether participants have a monological belief system regarding NPD and to test the hypothesis that lay beliefs would be affected by the above demographics. As can be seen in Table 4 the factor scores were not all correlated with each other. Superficiality and Social Problems correlated with Social Cognitive Explanations, Genetics and Early Negative Feelings, Treatability and Less Severe Treatment and Clinical Treatment. Business Abilities correlated with Genetics and Early Negative Events, Negative Feelings and Treatability and Less Severe Treatment. Fragility correlated with Social and Cognitive Explanations, Negative Feelings, Treatability and Less Severe Treatment. Social and Cognitive Explanations correlated with Treatability and Less Severe Treatment and Clinical Treatment. Genetics and Early Negative Events correlated with Clinical Treatment. Negative Feelings correlated with Treatability and Less Severe Treatment.

The study of mental illness correlated with fragility and age. Personal diagnosis of mental illness correlated with Treatability and Less Severe Treatment, Clinical Treatment and Superficiality and Social Problems. Qualifications correlated with Negative Feelings, Age and NPI Score. Gender correlated with Age and NPI Score. Age correlated with Fragility and Social and Cognitive Explanations and NPI Score. NPI Score correlated with Genetics and Early Negative Events, Negative Feelings and Social and Cognitive Explanations. This partly supports the hypothesis that participant's beliefs would be affected by whether people have studied mental illness, personal experience of mental illness and qualifications, gender, age and NPI Score because some beliefs were associated with these demographics but others were not.

\section{Discussion}

Regarding manifestations laypeople agreed on statements referring to superficiality and social problems, business abilities and fragility. Laypeople's beliefs regarding the aetiology of NPD factored into three components, social and cognitive explanations, negative feelings, and genetics and early negative events. Laypeople do not distinguish between social and cognitive factors suggesting an adoption of social-cognitive explanations by laypeople. No distinction was made between biological and psychological causes or genetics and early negative events. This demonstrates a lack of knowledge of NPD. Psychological explanations of aetiology were rated more positively than genetic explanations (genetic and early negative events) which supports past research 
Table 4. Bivariate Pearson correlations between the eight extracted factor scores, study of mental illness, interest in mental illness, qualification, gender, age and NPI score.

\begin{tabular}{|c|c|c|c|c|c|c|c|c|c|c|c|c|c|}
\hline & 12 & 3 & 4 & 5 & 6 & 7 & 8 & 9 & 10 & 11 & 12 & 13 & 14 \\
\hline 1) Superficiality and Social Problems & .00 & .00 & $.26^{* *}$ & $-.34^{* *}$ & -.11 & $.51^{* *}$ & $-.45^{* *}$ & .02 & $-.17^{*}$ & .00 & -.07 & .07 & -.07 \\
\hline 2) Business Abilities & & .01 & .13 & $.24^{* *}$ & $.16^{*}$ & $.17^{*}$ & .14 & -.08 & .02 & .04 & .04 & -.14 & .03 \\
\hline 3) Fragility & & & $.26^{* *}$ & .04 & $.20^{* *}$ & $.33^{* *}$ & .11 & $.13^{*}$ & -.08 & .04 & .10 & $-.19^{* *}$ & -.03 \\
\hline 4) Social and Cognitive Explanations & & & & .00 & .00 & $.64^{* *}$ & $.19^{*}$ & .03 & -.07 & -.01 & -.11 & $.17^{*}$ & $-.16^{*}$ \\
\hline 5) Genetics and Early Negative Events & & & & & .00 & -.11 & $.54^{* *}$ & -.10 & .07 & -.02 & -.02 & -.07 & $.14^{*}$ \\
\hline 6) Negative Feelings & & & & & & $.20^{* *}$ & .13 & .06 & -.03 & $.25^{* *}$ & -.03 & .05 & $-17^{*}$ \\
\hline 7) Treatability and Less Severe Treatment & & & & & & & .00 & .09 & $-.16^{* *}$ & .08 & -.02 & .03 & .02 \\
\hline 8) Clinical Treatment & & & & & & & & .05 & $.14^{*}$ & .01 & .06 & -.13 & -.09 \\
\hline 9) Study of Mental Illness & & & & & & & & & .14 & .05 & -.11 & $.26^{* *}$ & -.03 \\
\hline 10) Diagnosed with Mental Illness & & & & & & & & & & -.01 & -.00 & -.05 & -.03 \\
\hline 11) Qualifications & & & & & & & & & & & -.08 & $-.16^{*}$ & $-.15^{*}$ \\
\hline 12) Gender & & & & & & & & & & & & $-.21^{* *}$ & $.30^{* *}$ \\
\hline 13) Age & & & & & & & & & & & & & $.19^{* *}$ \\
\hline 14 NPI Score & & & & & & & & & & & & & \\
\hline
\end{tabular}

${ }^{*} p<.05 ;{ }^{* *} p<.001$.

(Furnham, Kirby, \& McClelland, 2011; Link, Phelan, Bresnahan, Stueve, \& Pescosolido, 1999). Laypeople distinguished clinical treatments from treatability and less severe treatments but not between psychological and biological treatments. Therefore laypeople may think in terms of the severity of treatment rather than making biological or psychological distinctions. This may be useful in everyday life but demonstrates poor knowledge of NPD.

Not all factors correlated with each other, suggesting that laypeople have a multi-logical belief system regarding NPD, with several different belief structures. This differs from Furnham, Daoud and Swami (2009) who found that laypeople have a monological belief system regarding psychopathy. This suggests that beliefs regarding different personality disorders do not all come from the same belief system. Most of the factors had low or moderate alphas and therefore caution should be taken when drawing conclusions from these results. However, the factors, especially when viewed alongside the findings of Furnham, Kirby and McClelland (2011) are useful in guiding our knowledge of laypeople's beliefs and demonstrating a lack of knowledge of NPD.

A limitation is that the current study's results could be due to order effects. Participants may have been less likely to correctly identify N2 and N3 than N1 because they thought that there could not be three NPD vignettes or that it was a test of at what severity narcissistic traits becomes a disorder. However this is unlikely because some participants did identify N3 correctly and the vignettes used appear very different which is supported by the content analysis.

All demographics tested except gender correlated with at least one factor. Diagnosis of a mental illness and NPI Score were the most predictive demographics. Personal experience of a disorder may influence beliefs regarding other disorders. This partly supports Furnham, Kirby and McClelland (2011) who found that personal experience of a mental illness related to lay theories of NPD because the diagnosis of a mental illness was related to three factors but not all factors. The findings also suggest that people's narcissistic traits influence their beliefs regarding NPD and that we form beliefs regarding personality around our own personality traits. This may make changing people's beliefs regarding personality disorders hard because some argue that personality cannot be dramatically changed (Costa \& McCrae, 1994) and it is therefore necessary to investigate whether this finding can be replicated and whether it applies to other personality disorders, for example whether peoples Schizotypal traits influence their beliefs regarding Schizotypal personality disorder. 
Our results partly confirm the hypothesis that the study of mental illness (Furnham, Daoud, \& Swami, 2009), personal experience of mental illness (Furnham, Abajian, \& McClelland, 2011), qualifications (Lauber, Carlos, \& Wolf, 2005), age (Fisher \& Goldney, 2003), gender (Wang, Adair, Fick, Lai, Waye, Jorm, \& Addington, 2007) and NPI score would relate to participants opinions of the manifestations, aetiology and treatment of NPD, the identification of vignettes and participants likeliness to suggest help. This is because all demographics tested except gender correlated with lay beliefs. Age, NPI score and the study of mental illnesses related to the correct identification of some vignettes. The findings partly support the past research except Wang, Adair, Fick, Lai, Waye, Jorm and Addington (2007). However demographics were more predictive of lay theories than mental health literacy when the past research that the hypothesis was based on investigated demographics relation to mental health literacy, except Furnham, Daoud and Swami (2009). Therefore the current study's findings do not support previous research in this way.

Overall our results suggest that how "abnormal” people deem certain traits to be is a key factor in identifying and suggesting help for personality disorders and mental illnesses. However, abnormality is not the only factor because differences in abnormality did not always lead to the same pattern of mental health literacy across participants. Knowledge of the specific disorder tested may also influence people's mental health literacy, especially regarding peoples likeliness to suggest help ratings because demographics did not influence this. Laypeople may not be willing to suggest help or label someone with a disorder unless they are sure that they have a problem. This is supported by the most frequent reason for a delay in seeking help is a lack of knowledge (Thompson, Hunt, \& Issakidis, 2004).

A limitation is that the current sample is not representative of the wider British population due to the method of sampling used. In addition, some of the items may require modification in subsequent research. This study is therefore useful as preliminary research into laypeople's beliefs regarding NPD but future research should aim to gain a more representative sample.

\section{Conclusion}

Lay people seem relatively ignorant about the causes, manifestations and treatment of Narcissism. There were few significant correlates of knowledge of NPD which suggests fairly widespread lack of information and data on this disorder.

\section{References}

Adler, G. (1986). Psychotherapy of the Narcissistic Personality Disorder Patient. American Journal of Psychiatry, 143, 430436.

American Psychiatric Association (1994). Diagnostic and Statistical Manual of Mental Disorders (4th ed.). Washington DC: American Psychiatric Association.

Ames, D. R., Rose, P., \& Anderson, C. P. (2006). The NPI-16 as a Short Measure of Narcissism. Journal of Research in Personality, 40, 440-450. http://dx.doi.org/10.1016/j.jrp.2005.03.002

Cain, N. M., Pincus, A. L., \& Ansell, E. B. (2008). Narcissism at the Crossroads: Phenotypic Description of Pathological Narcissism across Clinical Theory, Social/Personality Psychology, and Psychiatric Diagnosis. Clinical Psychology Review, 28, 638-656. http://dx.doi.org/10.1016/j.cpr.2007.09.006

Campbell, W. K., \& Miller, J. D. (2011). The Handbook of Narcissism and Narcissistic Personality Disorder: Theoretical Approaches, Empirical Findings and Treatments. New Jersey: John Wiley and Sons.

Cattell, R. B. (1966). The Scree Test for the Number of Factors. Multivariate Behavioural Research, 1, 245-276. http://dx.doi.org/10.1207/s15327906mbr0102 10

Comrey, A. L., \& Lee, H. B. (1992). A First Course in Factor Analysis. New Jersey: Lawrence Erlbaum Associates.

Cooper, A. M., \& Ronningstam, E. (1992). Narcissistic Personality Disorder. In A. Tasman, \& M. Riba (Eds.), Disorders of Narcissism: Diagnostic, Clinical, and Empirical Implications (pp. 53-74). Washington DC: American Psychiatric Press.

Costa Jr., P. T., \& McCrae, R. R. (1994). Set Like Plaster? Evidence for the Stability of Adult Personality. In T. Heatherton, \& J. Weinberger (Eds.), Can Personality Change? (pp. 21-40). Washington DC: American Psychological Association. http://dx.doi.org/10.1037/10143-002

DeWall, C. N., Buffardi, L. E., Bonser, I., \& Campbell, W. K. (2011). Narcissism and Implicit Attention Seeking: Evidence from Linguistic Analyses of Social Networking and Online Presentation. Personality and Individual Differences, 51, 57-62. http://dx.doi.org/10.1016/j.paid.2011.03.011 
Dickinson, K. A., \& Pincus, A. L. (2003). Interpersonal Analysis of Grandiose and Vulnerable Narcissism. Journal of Personality Disorder, 17, 188-207. http://dx.doi.org/10.1521/pedi.17.3.188.22146

Dunn, J., \& Plomin, R. (1990). Separate Lives: Why Siblings Are so Different. New York: Basic Books.

Fisher, L. J., \& Goldney, R. D. (2003). Differences in Community Mental Health Literacy in Older and Younger Australians. International Journal of Geriatric Psychiatry, 18, 33-40. http://dx.doi.org/10.1002/gps.769

Furnham, A., Abajian, N., \& McClelland, A. (2011). Psychiatric Literacy and Personality Disorders. Psychiatry Research, 189, 110-114. http://dx.doi.org/10.1016/j.psychres.2011.02.024

Furnham, A., Daoud, J., \& Swami, V. (2009). How to Spot a Psychopath. Social Psychiatry and Psychiatric Epidemiology, 44, 464-472. http://dx.doi.org/10.1007/s00127-008-0459-1

Furnham, A., Kirby, V., \& McClelland, A. (2011). Non Experts Understanding of Three Major Personality Disorders. Personality and Mental Health, 5, 43-56. http://dx.doi.org/10.1002/pmh.150

Harman, M. J., \& Waldo, M. (2004). Relationship Enhancement Family Therapy with Narcissistic Personality Disorder. In M. MacFarland (Ed.), Family Treatment of Personality Disorders (pp. 335-359). Philadelphia: Haworth Press.

Kernberg, O. F. (1975). Borderline Conditions and Pathological Narcissism. New York: Aronson.

Kernberg, O. F. (2010). Narcissistic Personality Disorder. In J. F. Clarkin, P. Fonagy, \& G. O. Gabbard (Eds.), Psychodynamic Therapy for Personality Disorders. A Clinical Handbook (pp. 257-287). Arlington: American Psychiatric Publishing.

Kline, P. (1986). Handbook of Test Construction. London: Routledge and Kegan Paul.

Koerner, K., Kohlenberg, R. J., \& Parker, C. R. (1996). Diagnosis of Personality Disorder: A Radical Behavioural Alternative. Journal of Consulting and Clinical Psychology, 64, 1169-1176. http://dx.doi.org/10.1037/0022-006X.64.6.1169

Kohut, H. (1971). An Analysis of the Self: A Systematic Approach to the Psychoanalytic Treatment of Narcissistic Personality Disorder. Chicago: University of Chicago Press.

Kohut, H. (1977). The Restoration of the Self. Madinson: International Universities Press.

Lasch, C. (1978). The Culture of Narcissism: American Life in an Age of Diminishing Expectations. New York: Norton.

Lauber, C., Carlos, N., \& Wulf, R. (2005). Lay Beliefs about Treatment for People with Mental Illness and Their Implications for Antistigma Strategies. Canadian Journal of Psychiatry, 50, 745-752.

Link, B. G., Phelan, J. C., Bresnaham, M., Stueve, A., \& Pescosolido, B. A. (1999). Public Conceptions of Mental Illness: Labels, Causes, Dangerousness, and Social Distance. American Journal of Public Health, 89, 1328-1333. http://dx.doi.org/10.2105/AJPH.89.9.1328

Miller, J. D., Hoffman, B. J., Gaughan, E. T., Gentile, B., Maples, J., \& Campbell, K. W. (2011). Grandiose and Vulnerable Narcissism: A Nomological Network Analysis. Journal of Personality, 79, 1013-1042. http://dx.doi.org/10.1111/j.1467-6494.2010.00711.x

Miller, J. D., Widiger, T. A., \& Campbell, W. K. (2010). Narcissistic Personality Disorder and the DSM-5. Journal of Abnormal Psychology, 119, 640-649. http://dx.doi.org/10.1037/a0019529

Oldham, J. M., \& Morris, L. B. (1995). New Personality Self Portrait. New York: Bantam Book.

Otway, L. J., \& Vignoles, V. L. (2006). Narcissism and Childhood Recollections: A Quantitative Test of Psychoanalytic Predictions. Personality and Social Psychology Bulletin, 32, 104-116. http://dx.doi.org/10.1177/0146167205279907

Paris, J. (1996). Social Factors in the Personality Disorders: A Biopsychosocial Approach to Aetiology and Treatment. New York: Cambridge University Press. http://dx.doi.org/10.1017/CBO9780511722165

Pincus, A. L., \& Lukowitsky, M. R. (2010). Pathological Narcissism and Narcissistic Personality Disorder. Annual Review of Clinical Psychology, 6, 421-446. http://dx.doi.org/10.1146/annurev.clinpsy.121208.131215

Ritter, K., Dziobek, I., Preisler, S., Ruter, A., Vater, A., Fydrich, T., Lammers, C. H., Heekeran, H. R., \& Roepke, S. (2011). Lack of Empathy in Patients with Narcissistic Personality Disorder. Psychiatry Research, 187, 241-247. http://dx.doi.org/10.1016/j.psychres.2010.09.013

Ronningstam, E. (2011). Narcissistic Personality Disorder in DSM-V-In Support of Retaining a Significant Diagnosis. Journal of Personality Disorders, 25, 248-259. http://dx.doi.org/10.1521/pedi.2011.25.2.248

Ronningstam, E., \& Gunderson, J. (1991). Differentiating Borderline Personality Disorder from Narcissistic Personality Disorder. Journal of Personality Disorder, 5, 225-232. http://dx.doi.org/10.1521/pedi.1991.5.3.225

Ronningstam, E., \& Gunderson, J. G. (1990). Identifying Criteria for Narcissistic Personality Disorder. American Journal of Psychiatry, 147, 918-922.

Rose, P. (2001). The Happy and Unhappy Faces of Narcissism. Personality and Individual Differences, 33, 379-391. http://dx.doi.org/10.1016/S0191-8869(01)00162-3

Rothbart, M. K. (1991). Temperament: A Developmental Framework. Explorations in Temperament. New York: Plenum 
Press.

Rutter, M., \& Quinton, D. (1984). Long-Term Follow-Up of Women Institutionalized in Childhood: Factors Promoting Good Functioning in Adult Life. British Journal of Developmental Psychology, 18, 225-234.

Stinson, F. S., Dawson, D. A., Goldstein, R. B., Chou, S. P., Huang, B., Smith, S. M. et al. (2008). Prevalence, Correlates, Disability, and Comorbidity of DSM-IV Narcissistic Personality Disorder: Results from the Wave 2 National Epidemiologic Survey on Alcohol and Related Conditions. Journal of Clinical Psychiatry, 69, 1033-1045. http://dx.doi.org/10.4088/JCP.v69n0701

Tabachnick, B. G., \& Fidell, L. S. (2001). Using Multivariate Statistics (4th ed.). New York: HarperCollins.

Thomaes, S., \& Bushman, B. J. (2011). Mirror Mirror on the Wall, Who's the Most Aggressive of Them All? Narcissism, Self-Esteem, and Aggression. Self Views and Aggression, 1-25.

Thompson, A. E., Hunt, C., \& Issakidis, C. (2004). Why Wait? Reasons for Delay and Prompts to Seek Help for Mental Health Problems in an Australian Clinical Sample. Social Psychiatry and Psychiatric Epidemiology, 39, 810-817.

Turner, R. M. (1994). Borderline, Narcissistic, and Histrionic Personality Disorders. In M. Hersen, \& R. T. Ammerman (Eds.), Handbook for Prescriptive Treatments for Adults (pp. 393-420). New York: Plenum.

Twenge, J., \& Campbell, K. (2009). The Narcissism Epidemic Living in the Age of Entitlement. New York: Free Press.

Wang, J. L., Adair, C., Fick, G., Lai, D., Perry, B., Jorm, A. F., \& Addington, D. (2007). Depression Literacy in Alberta: Findings from a General Population Sample. Canadian Journal of Psychiatry, 52, 442-449.

Widiger, T. A., Simonsen, E., Krueger, R., Livesley, W. J., \& Verheul, R. (2009). Personality Disorder Research Agenda for the DSM-V. Journal of Personality Disorders, 19, 315-338. http://dx.doi.org/10.1521/pedi.2005.19.3.315

Wink, P. (1991). Two Faces of Narcissism. Journal of Personality and Social Psychology, 61, 590-597. http://dx.doi.org/10.1037/0022-3514.61.4.590 
Scientific Research Publishing (SCIRP) is one of the largest Open Access journal publishers. It is currently publishing more than 200 open access, online, peer-reviewed journals covering a wide range of academic disciplines. SCIRP serves the worldwide academic communities and contributes to the progress and application of science with its publication.

Other selected journals from SCIRP are listed as below. Submit your manuscript to us via either submit@scirp.org or Online Submission Portal.
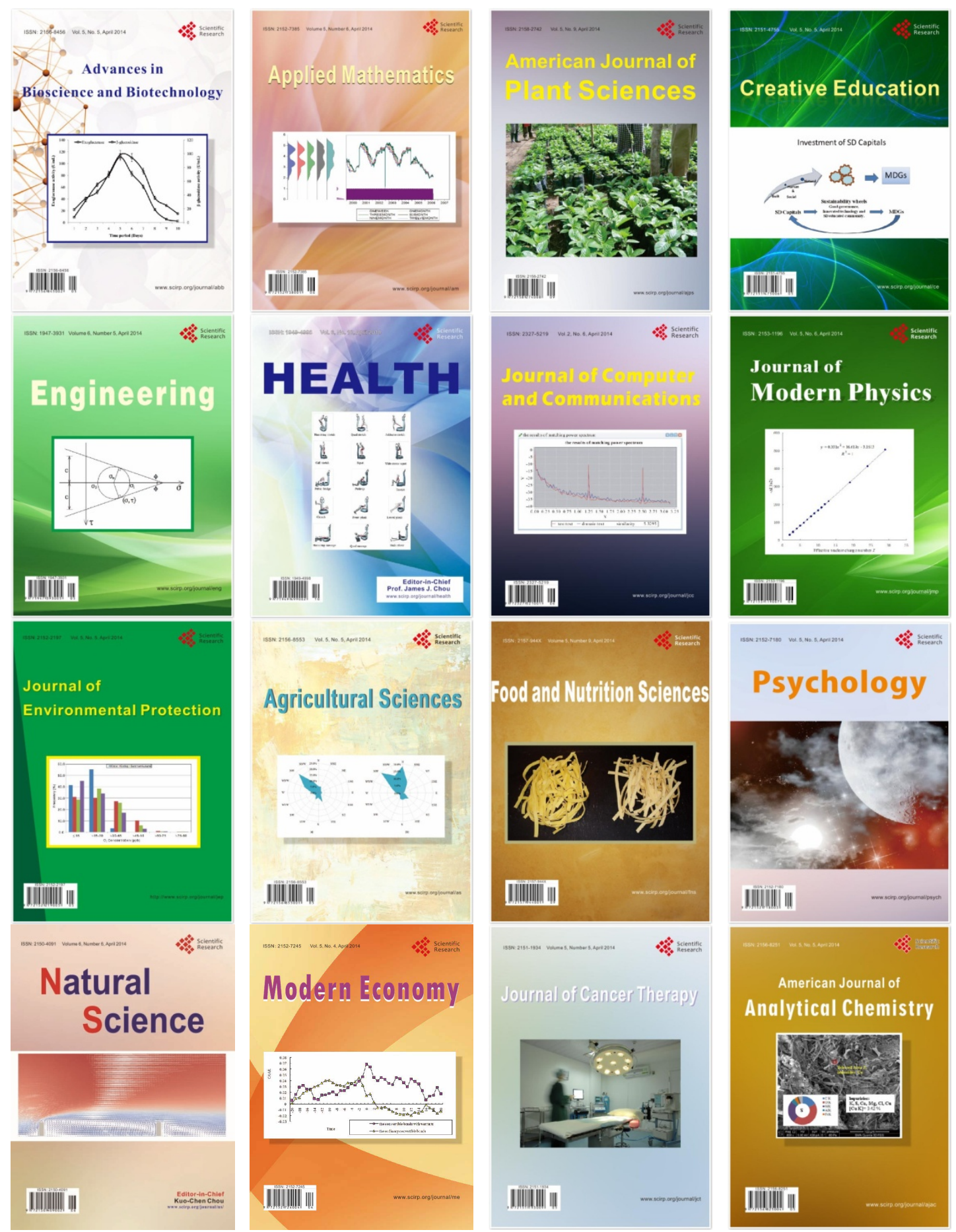